NEUES AUS DER INDUSTRIE

\section{INTECO liefert Sonderstahlwerk an SeAH Changwon Integrated Special Steel, Korea}

Ende November 2015 erhielt INTECO den Auftrag zur Konstruktion und Lieferung eines kompletten Sonderstahlwerks von $\mathrm{SeAH}$ Changwon Integrated Special Steel. Der Auftragsrahmen beinhaltet einen 8t Vakuuminduktionsofen, eine 8 und eine $4 \mathrm{t}$ Elektroschlacke Umschmelzanlage sowie einen 8t Vakuumlichtbogenofen.

Nach dem Sonderstahlwerk für Ruspolymet und einem weiteren Kunden in Asien ist dies bereits das dritte komplette Sonderstahlwerk in einem Zeitraum von 2 Jahren, welches von INTECO gebaut wird.

Das Team des koreanischen Stahlproduzenten, die Experten von INTECO und der koreanische Fertigungspartner haben bereits bei der Abwicklung des gemeinsamen Vorgängerprojektes, einem 150t Pfannenofen plus VD lieferung aller Anlagen innerhalb von Anlage, ihre gute Kooperation unter Beweis gestellt. Bei diesem herausfordernden Projekt ist eine Aus9 Monaten vereinbart. Die Inbetriebnahme ist für Herbst 2016 geplant.

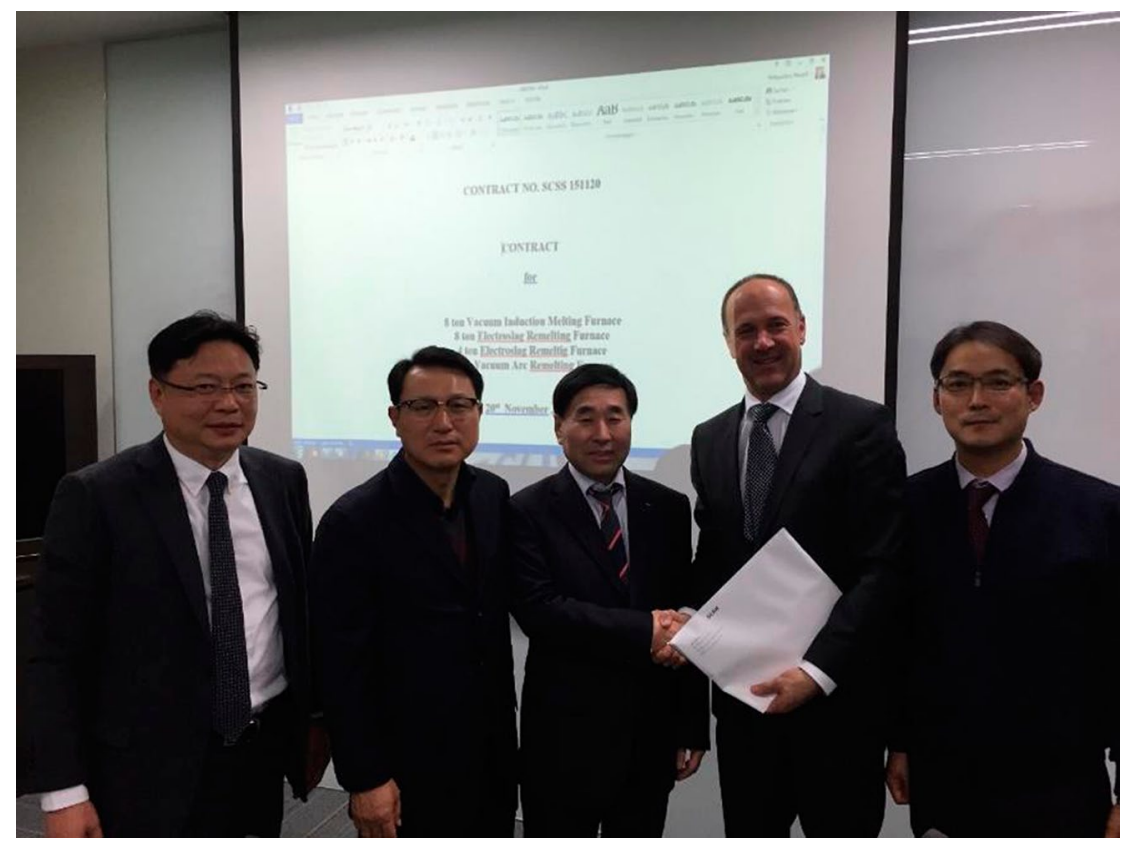

